\title{
Utility of transrectal ultrasonography guidance and seven key elements of operative skill for early recovery of urinary continence after laparoscopic radical prostatectomy
}

\author{
HARUHITO AZUMA, NAOKAZU IBUKI, TERUO INAMOTO, KOHEI KOYAMA, SHINYA UTIMOTO, \\ YUTAKA FUJISUE, YOICHI MIZUTANI, HAYAHITO NOMI, TAKANOBU UBAI and YOJI KATSUOKA
}

\author{
Department of Urology, Osaka Medical College, Takatsuki, Osaka 569-8686, Japan
}

Received September 9, 2010; Accepted November 16, 2010

DOI: $10.3892 /$ ijo.2010.865

\begin{abstract}
In the present study, we report the utility of transrectal ultrasonography guidance for laparoscopic radical prostatectomy (LRP), and the effect of a novel surgical approach of 'seven key elements of operative skill for the early recovery of urinary continence' ('7 key elements'). Among 170 patients who underwent laparoscopic prostatectomy between July 2007 and June 2010, 72 were treated on the basis of these 7 key elements (group 1), which included the preservation of 1) endopelvic fascia, 2) bladder neck, 3) pelvic nerve, 4) membranous urethra, 5) urethral sphincter and fixation of the organ positioning with 6) bladder neck sling suspension, and 7) restoration of the Denonvilliers' fascia, while the remaining 98 were not (group 2). We compared the data for the two groups with regards to the time taken for recovery of continence, and post-operative course. Application of the 7 key elements led to significantly earlier recovery of continence. In group 1, the number of urinary pads used after surgery was significantly reduced at all of the examined timepoints after surgery $(1,3,6$ and 12 months) $(\mathrm{p}<0.0001)$. In group 1 , more than half of the patients $(54 \%)$ achieved urinary continence within 3 months, 93\% achieved it within 6 months, and all patients had achieved it within 12 months after surgery. However, in group $2,<10 \%$ of the patients $(8.5 \%, \mathrm{p}<0.0001)$ achieved continence within 3 months, and $23 \%(\mathrm{P}<0.0001)$ achieved it within 6 months. Therefore, the results show that the 7 key elements of operative skill with transrectal ultrasonography guidance significantly improve the outcome of LRP, reducing the time required for the recovery of continence.
\end{abstract}

\section{Introduction}

We report the utility of operative skill using transrectal ultrasonography guidance for laparoscopic radical prostatectomy

Correspondence to: Dr Haruhito Azuma, Department of Urology, Osaka Medical College, Takatsuki, Osaka 569-8686, Japan

E-mail: uro004@poh.osaka-med.ac.jp

Key words: transrectal ultrasonography guidance, bladder-urethral angle, urethral length
(LRP). We selected seven elements of operative skill for the minimization of urinary incontinence ('the 7 elements' hereafter) among several proposed by urological experts, based on our experience of open surgery as well as details from other studies. The 7 elements mainly consisted of the preservation of intrapelvic tissues including 1) minimal incision of the endopelvic fascia, 2) bladder neck, 3) bilateral nerve-sparing surgery, 4) the membranous urethra, 5) the urethral sphincter muscle and fixation of organ positioning with 6) bladder neck sling suspension, and 7) restoration of the Denonvilliers' musculofascial plate. Transrectal ultrasonography (TRUS) guidance, which provides sagittal images of the pelvic organs, including the prostate, bladder and rectum, in real-time, was of great assistance in incorporating these 7 elements through the enhancement of technical skill, and also helped reduce the incidence of intra-operative complications. Moreover, ultrasonography with Doppler imaging visualizes the neurovascular bundle, which is crucial for successful nerve-sparing surgery.

In principle, we tried to incorporate all of the 7 elements for all the patients, although ultimately certain patients could not be treated with some of them. We retrospectively studied the relationship between the use of each element and the continence status of each patient, and examined the significance of each element for the early recovery of urinary continence. We found that patients who were treated with all the 7 elements showed significantly earlier recovery of urinary continence, with a reduced number of urinary pads and a higher continence rate, at all of the post-surgery time-points examined (1, 3, 6 and 12 months), compared to the others.

Herein, we outline the details of the surgical procedure involving the 7 elements and the confirmation of surgical success, together with the current outcomes in terms of recovery of urinary continence.

\section{Patients and methods}

Patients. The subjects were 170 patients who underwent laparoscopic total prostatectomy at the Urology Department of Osaka Medical College between June 2007 and June 2010. The study was reviewed and approved by the Institutional Review Board of Osaka Medical College. Patients were informed of the investigational nature of the study and provided written informed consent prior to enrollment. The 
median age was 70 years (51-82 years), and the median duration of follow-up was 14 months (2-38 months). The preoperative median PSA level was $8.11 \mathrm{ng} / \mathrm{ml}(2.87-73 \mathrm{ng} / \mathrm{ml})$. Pre-operative pathological examination of biopsy specimens revealed adenocarcinoma in all cases, and the histological grade in terms of the Gleason score was $\leq 6$ in 56 cases $(32.9 \%), 7$ in $52(30.6 \%)$, and $\geq 8$ in 62 cases (36.5). The preoperative clinical staging was T1c in 80 cases $(47.1 \%)$, T2a in $43(25.3 \%), \mathrm{T} 2 \mathrm{~b}$ in $30(17.6 \%), \mathrm{T} 2 \mathrm{c}$ in $16(9.4 \%)$ and T3a in 1 case $(0.6 \%)$.

\section{Surgical technique}

Port position. Fig. 1 shows the schema of the port positions, which we adopted after various trials.

Set-up of transrectal probe for ultrasonography. We used an ultrasonography system intra-operatively with the transrectal probe. The probe was inserted into the rectum of the patients with partial fine control so that it was able to reflect the bladder and prostate through the rectal wall, providing a sagittal image from any angle. All of the operative procedures were recorded on a DVD recorder. Using this approach, we were able to obtain sagittal images of the pelvic organs, including the prostate, bladder and rectum, in real-time and from any angle according to need during the operation. These images were of great assistance in gaining an easy grasp of the total shape, apex (distal end) and base (proximal end) of the prostate, contributing to a better outcome when incorporating the 7 elements through the enhancement of operative and technical skill, and also helped reduce the incidence of intra-operative complications.

Details of the operative procedure incorporating the 7 key elements

Key element 1: Maximum preservation of the endopelvic fascia. The junction of the endopelvic fascia, representing the boundary between the fascia covering the prostate and that covering the levator ani muscle, is bluntly incised (Fig. 2a and $b$ ). The separation at an adequate depth without sharp dissection to preserve the endopelvic fascia is the key to the reduction of post-operative urinary incontinence.

Key element 2: Maximum preservation of the bladder neck. The TRUS image provides visualization of the sagittal aspect of the prostate and bladder neck. The contour of the prostate and the boundary between the prostate and bladder neck can be easily confirmed on the ultrasound image by moving the balloon catheter (with the cuff set to $20 \mathrm{ml}$ ) and by pushing the boundary between the prostate and bladder neck with forceps (Fig. 2c and d). After confirming the boundary between the prostate and bladder neck, the outermost fascial layer continuing from the prostate to the bladder neck, is sharply cut (Fig. 2e and f), and the muscle layer of the bladder is detached from the prostate using a spatula-type electrode (opti-4 suction pipe, Surgiwand ${ }^{\mathrm{TM}}$ II spatula tip; Tyco) as if peeling the bladder from the basal prostate, preserving the bladder neck as much as possible (Fig. $2 \mathrm{~g}$ and $\mathrm{h}$ ).

Key element 3: Bilateral nerve-sparing procedure. Except for $\mathrm{T} 3$ tumors, we found that there was no difference in the

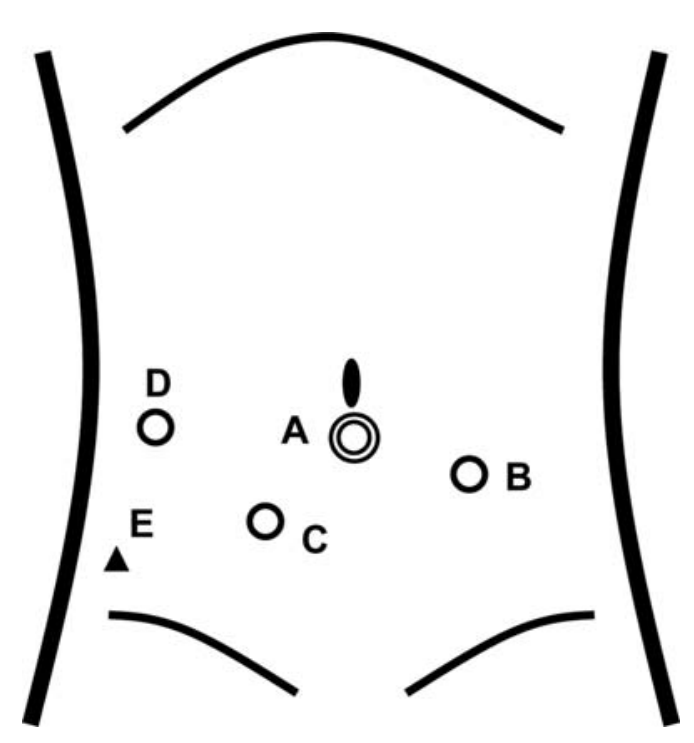

Figure 1. Port positions. (Port A) A 12-mm trocar with a balloon (Blunt Tip Trocar $^{\mathrm{TM}}$, Tyco) is inserted as a camera port. (Port B) The surgeon places the left hand $12-\mathrm{mm}$ port at a site $1 / 3$ laterally along a line connecting the navel and the left anterior superior iliac spine. (Port C) The surgeon places the right hand 12-mm port slightly to the right of the midline between Port A and the pubic bone. (Port D) The assistant places the left hand 12-mm port lateral to the right rectus abdominis muscle at the Port A level. (Port E) The assistant places the right hand 5-mm port slightly lateral to the McBurney point. The surgeon uses Ports $\mathrm{B}$ and $\mathrm{C}$ in the dissection step, and differentially uses the right Ports $\mathrm{C}, \mathrm{D}$ and $\mathrm{E}$, for the handling of the needle according to the required angle and direction.

rate of surgical margin positivity or the rate of post-operative PSA relapse between patients who had undergone bilateral nerve-sparing and patients who had not. We therefore now routinely perform nerve-sparing operations to allow earlier recovery of urinary continence in patients with localized cancer (under T2 tumors).

The rectum should be bluntly dissected from the dorsal surface of the prostate, so that the neurovascular bundle is retained on the rectal side of the lateral pedicle separated from the prostate. Ultrasonography through the rectal wall, which provides a sagittal image of the rectal wall, is of great assistance in avoiding rectal injury (Fig. 3a-d). Moreover, Doppler ultrasound, which visually displays the blood flow of the neurovascular bundle, is extremely helpful in nervesparing surgery. After confirming that as much of the neurovascular bundle as possible is retained on the rectal side, any remaining tissue is clipped as close as possible to the prostate, and is sequentially cut up to the apex, using cold scissors (Fig. 3e-h). The surgeon should not use electrocoagulation during this process in order to avoid subjecting the neurovascular bundle in the lateral pedicle to injury (1).

Key element 4: Maximum preservation of the external urethral sphincter muscle. The dorsal vein complex (DVC), urethra, and external urethral sphincter are visualized by ultrasonography imaging. After confirming their anatomical positions and relationships, the entire DVC is double-ligated as distantly as possible, but proximal to the urethral sphincter without suturing it (Fig. 4a and b). The ligation of the DVC should be performed entirely by the bunching procedure, which prevents excessive bleeding and protects the external 

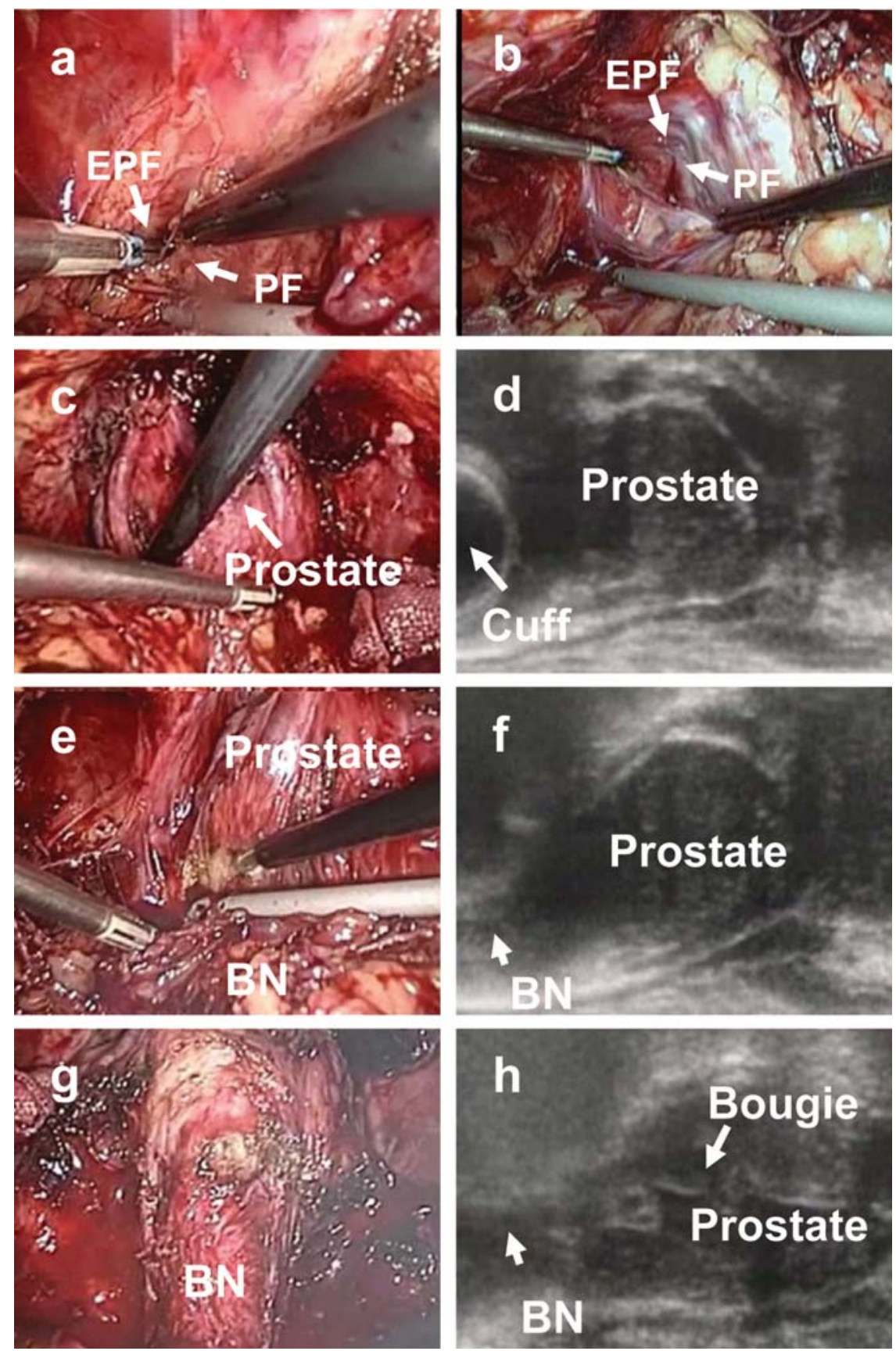

Figure 2. Representative images obtained by optical video (a, b, c, e and g), and by ultrasonography (f, h and j) during the surgical procedure for endopelvic fascia preservation ( $a$ and b), and bladder neck preservation (c-h). (a) The endopelvic fascia is stretched with forceps on both sides (using a bipolar coagulator and suction pipe). (b) The junction between the fascia covering the prostate and that covering the levator ani muscle is bluntly incised. (c and d) The boundary between the prostate and bladder neck is confirmed by pushing with forceps. The ultrasound image is of great assistance in recognizing the boundary between the prostate and bladder neck, displaying the sagittal aspect of the prostate, bladder neck, and balloon catheter with the cuff set at $20 \mathrm{ml}$. (e and f) The outermost fascia continuing from the prostate to the bladder neck is sharply cut, while confirming the boundary between them on the ultrasound image. (g and $\mathrm{h}$ ) The muscle layer of the bladder is detached from the prostate using a spatula-type electrode, as if peeling the bladder from the basal prostate, while preserving as much of the bladder neck as possible. BN, bladder neck; EPF, endopelvic fascia; PF, prostatic fascia.

urethral sphincter from injury due to electrocoagulation. The ligated DVC is cut at the proximal side with a $1-\mathrm{cm}$ margin to the external sphincter, avoiding any injury to it, while pulling the prostate to the front, providing countertraction (Fig. $4 \mathrm{c}$ and d).

Key element 5: Maximum preservation of the membranous urethra (preservation of urethral length). After cutting the
DVC, the bilateral neurovascular bundles are bluntly peeled from the urethra (Fig. 4e and f). The resection line is set as proximally as possible while pulling the apical prostate to the front, providing countertraction to the urethra, which is extended to its maximum possible length, and ensuring that no prostate tissue remains (Fig. 4g). Ultrasonography, which provides a sagittal image of the prostate, aids in the recognition of the prostate apex, which is very helpful in reducing 

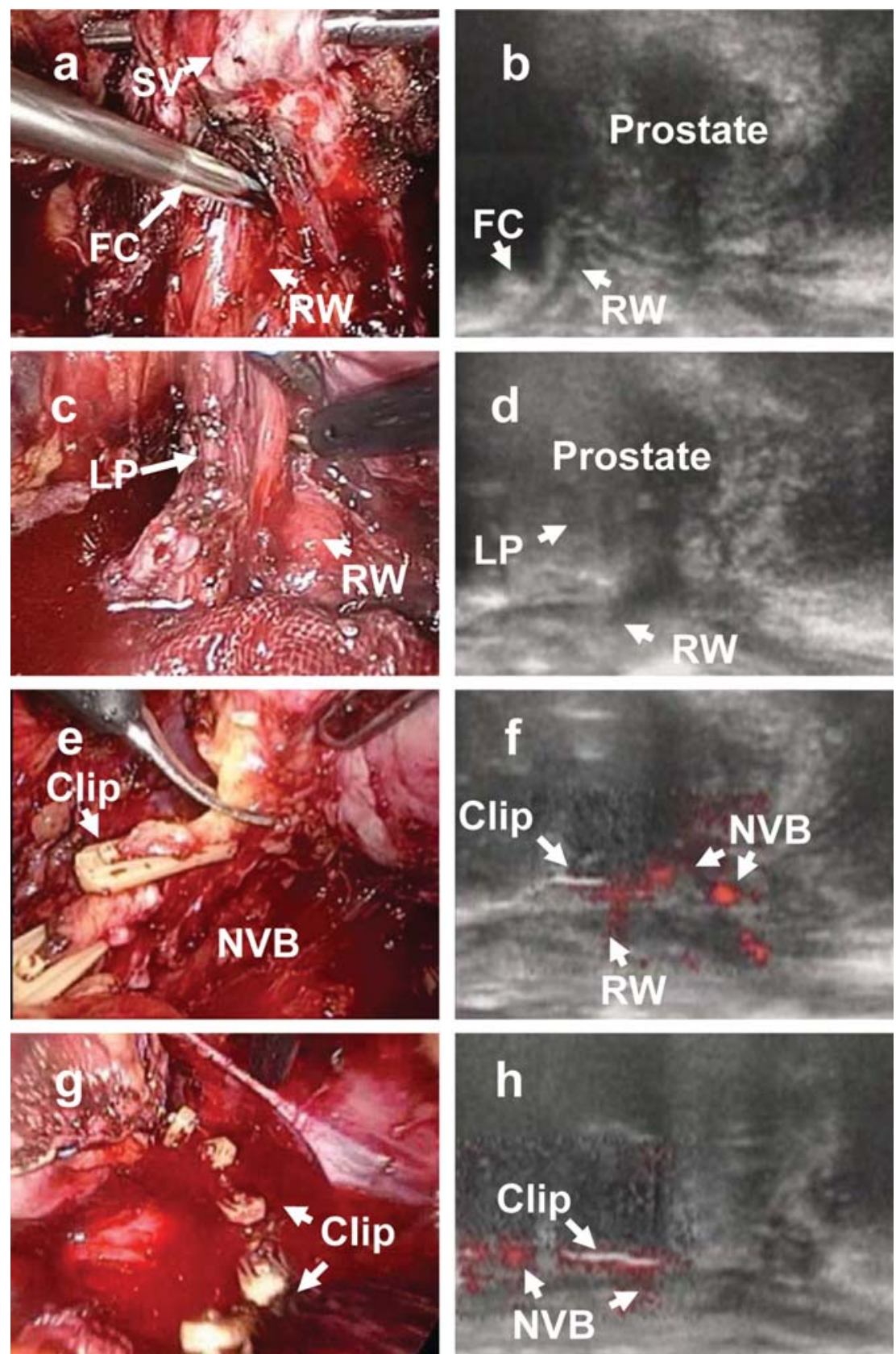

Figure 3. Optical (a, c, e and g) and ultrasound (b, d, f and h) images of the nerve-sparing procedure. (a and b) The rectal wall is confirmed using ultrasonography by pushing it with forceps. (c and d) The rectum is bluntly dissected from the dorsal surface of the prostate, leaving the connective tissue between the rectum and the prostate, the 'lateral pedicle'. The ultrasound image is of great assistance in recognizing the rectal wall and avoiding rectal injury. (e and f) After confirming that as much of the neurovascular bundle as possible is retained on the rectal side, the lateral pedicle is clipped as closely as possible to the prostate, and then cut with cold scissors. The Doppler ultrasound image through the rectal wall is of great assistance in recognizing the neurovascular bundle and retaining it on the rectal side. ( $\mathrm{g}$ and $\mathrm{h}$ ) The lateral pedicle is clipped and is sequentially cut up to the apex, so that the whole neurovascular bundle is separated from the prostate, and retained on the rectal side. Preservation of the neurovascular bundle is confirmed on the Doppler ultrasound image. FC, forceps; LP, lateral pedicle; NVB, neurovascular bundle; RW, rectal wall; SV, seminal vesicle.

the probability of surgical margin positivity. The membranous urethra is retained as long as possible, whithout injuring the sphincter muscle surrounding the urethra. The length of the membranous urethra is measured from the ultrasound image (Fig. 4h), and then cut (Fig. $4 \mathrm{i}$ and j). When $>2.1 \mathrm{~cm}$ of the membranous urethra was preserved, we considered that urethral preservation was successful, as the average length of the membranous urethra was $1.65 \pm 0.23 \mathrm{~cm}$ in patients in this series before prostatectomy, and average length in addition to the double value of standard deviation (mean $+2 \mathrm{SD}$ ), was
$2.11 \mathrm{~cm}$. At this point, to avoid injuring the urethral sphincter with heat, and to preserve the nerves distributed to the levator ani muscle and the ones innervating the sphincter muscle of the external urethra and blood vessels, as little electrocoagulation as possible is employed (2).

Key element 6: Sling suspension of the bladder neck (preservation of the puboprostatic ligament and suture with the bladder neck). Preservation of the puboprostatic ligament is achieved as follows: While pulling the prostate to the front, 

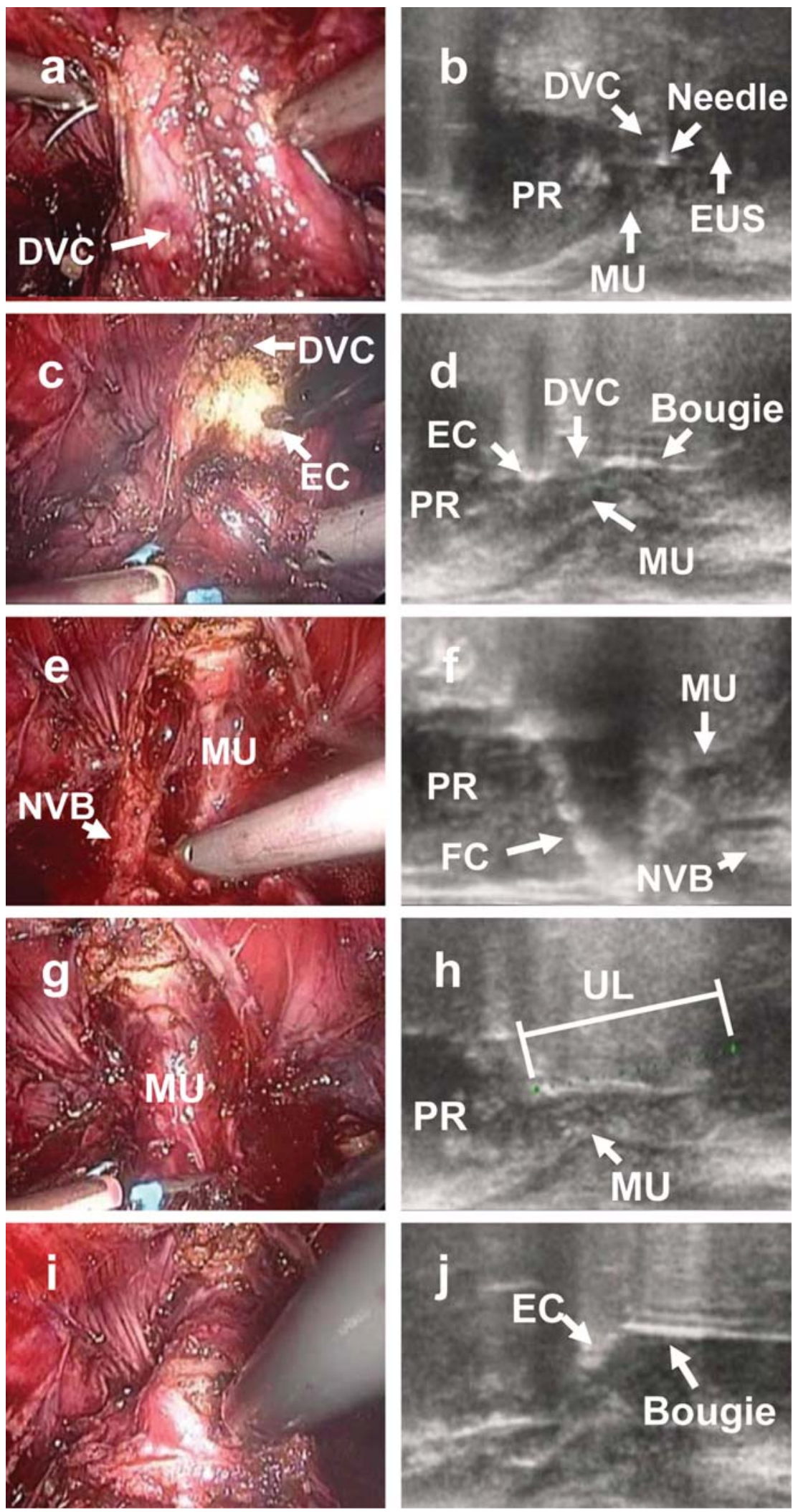

Figure 4. Representative images during the surgical procedure for maximum preservation of the membranous urethra (a-d) and external urethral sphincter preservation (e-j). (a and b) The DVC, membranous urethra, and external urethral sphincter are visualized by ultrasound imaging. After confirming their anatomical positions and relationships, the entire DVC is double-ligated as distally as possible to avoid injuring the urethral sphincter. (c and d) The ligated DVC is cut at the proximal side with a $1-\mathrm{cm}$ margin to the external sphincter, avoiding any injury to it, while pulling the prostate to the front, providing countertraction. (e and f) The bilateral neurovascular bundles are bluntly peeled from the urethra. The ultrasound image is helpful in recognizing the neurovascular bundles. ( $\mathrm{g}$ and $\mathrm{h}$ ) The length of the membranous urethra is measured from the ultrasound image. When the membranous urethra was preserved for a length of $>2.1 \mathrm{~cm}$, we considered that urethral preservation was successful. ( $\mathrm{i}$ and $\mathrm{j}$ ) The resection line is set at the most proximal site possible while pulling the apical prostate to the front, providing countertraction to the urethra and extending it to its maximum possible length, and also ensuring that no prostate tissue remains, followed by cutting. Ultrasonography, which provides a sagittal image of the prostate, is helpful in recognizing the apex of the prostate. DVC, dorsal vein complex; EC, electric scissors; EUS, external urethral sphincter; FC, forceps; MU, membranous urethra; NVB, neurovascular bundle; PR, prostate; UL, urethral length. 

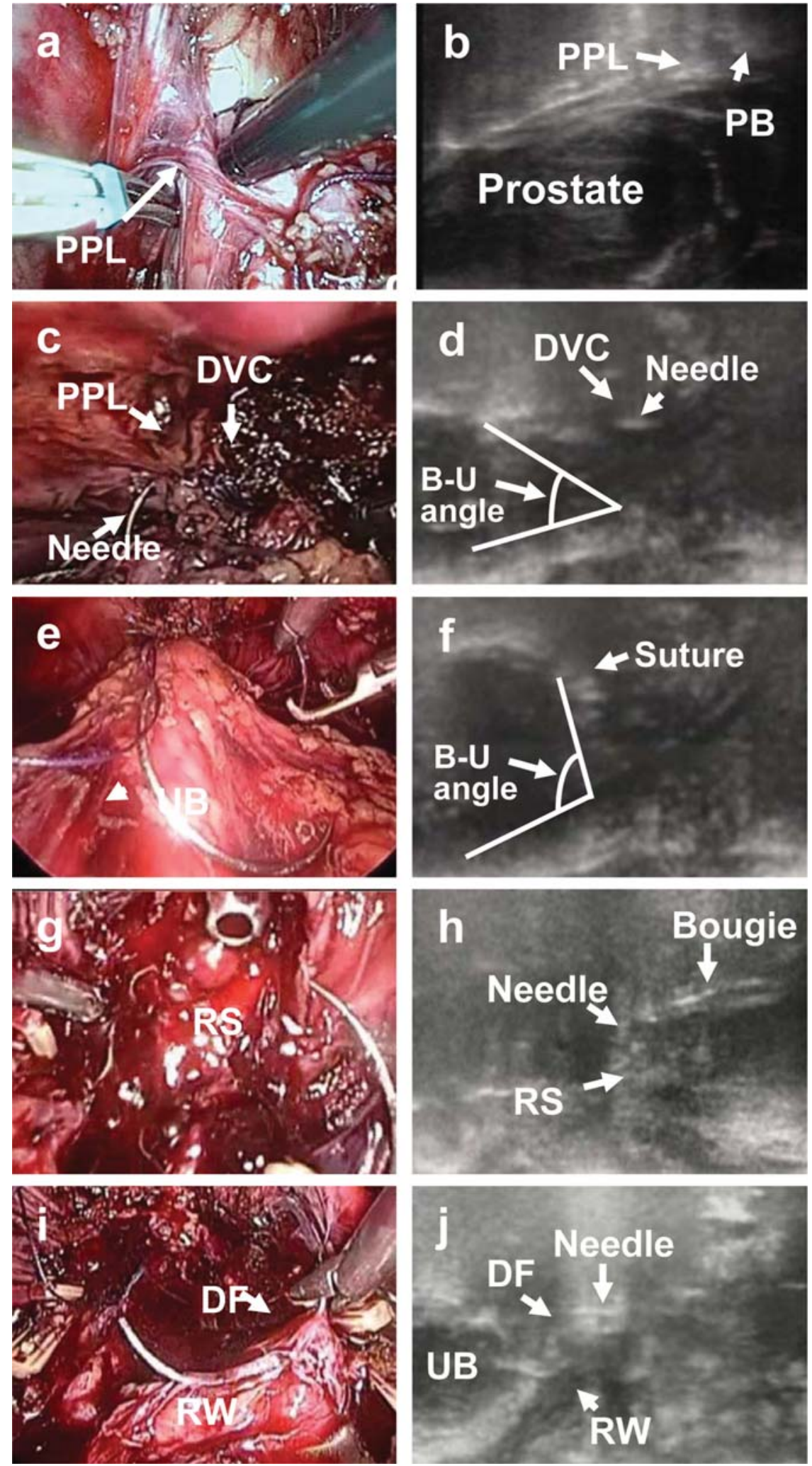

Figure 5. Representative images during the surgical procedure for sling suspension of the bladder neck (and for reconstruction of the posterior support) obtained by optical video ( $\mathrm{a}, \mathrm{c}$ and $\mathrm{e}$ ) and ultrasonography ( $\mathrm{b}, \mathrm{d}$ and $\mathrm{f}$ ). ( $\mathrm{a}$ and $\mathrm{b}$ ) The puboprostatic ligament is dissected from the prostate, while pulling the prostate towards the front. (c and d) After the completion of bladder neck suturing at the 12 o'clock position, the preserved bilateral puboprostatic ligaments are stitched with the same thread. The ultrasound image indicates the thickness of the DVC, and the position of the needle. The 'bladder-urethral angle', which is the angle between the posterior wall of the bladder and the membranous urethra when the bladder is filled with $50 \mathrm{ml}$ of water, was $<50$ degrees before completing the sling suspension. (e and f) The bilateral puboprostatic ligaments, the DVC and the bladder neck at the 12 o'clock position are sutured so as to place the bladder neck at its original position relative to the prostate. The 'bladder-urethral angle', as evaluated from the ultrasound image, was $>83$ degrees, which was considered to indicate successful execution of the sling-suspension. ( $\mathrm{g}$ and $\mathrm{h}$ ) The prostatic fascia and urethral rhabdosphincter are stitched with 2-0 Vicryl suture. The ultrasound image demonstrates the anatomical position of the prostatic fascia and urethral rhabdosphincter. (i and j) The prostatic fascia and urethral rhabdosphincter are anchored with the remaining portion of the Denonvilliers' fascia cut on the urethral side. The ultrasound image provides a sagittal image of the rectal wall, confirming the stitching of the Denonvilliers' fascia. B-U angle, bladder-urethral angle; DF, Denonvilliers' fascia; DVC, dorsal vein complex; MFP, musculofascial plate; PPL, pubprostatic ligament; RS, rhabdosphincter, RW, rectal wall; UB, urinary bladder. 
Table I. Patient characteristics in both groups.

\begin{tabular}{|c|c|c|c|}
\hline Characteristics & Group $1(n=72)$ & Group $2(n=98)$ & P-value \\
\hline \multicolumn{4}{|l|}{ Age (years) } \\
\hline Median & 69 & 70 & 0.3221 \\
\hline (Range; 1st-3rd QU) & $(51-79 ; 65-73)$ & $(52-82 ; 66-74)$ & \\
\hline \multicolumn{4}{|l|}{ BMI } \\
\hline Median & 22.8 & 23.1 & 0.6256 \\
\hline (Range; 1st-3rd QU) & $(18.3-31.5 ; 21.6-25.2)$ & $(15.9-28.4 ; 21.3-24.5)$ & \\
\hline \multicolumn{4}{|c|}{ Follow-up period (months) } \\
\hline Median & 12 & 15 & 0.0018 \\
\hline (Range; 1st-3rd QU) & $(2-24 ; 7-19)$ & $(2-38 ; 10-27)$ & \\
\hline \multicolumn{4}{|l|}{ PSA (ng/l) } \\
\hline Median & 8.125 & 8.110 & 0.9442 \\
\hline (Range; 1st-3rd QU) & $(2.9-73 ; 6.5-12.9)$ & $(4.1-50 ; 6.3-12.2)$ & \\
\hline \multicolumn{4}{|l|}{ Prostate volume (ml) } \\
\hline Median & 36.1 & 29.0 & 0.1824 \\
\hline (Range; 1st-3rd QU) & $(11.4-96.6 ; 25.7-46.5)$ & $(11-86.4 ; 22.3-38.9)$ & \\
\hline Neoadjuvant, no. (\%) & $56(77.8)$ & $58(59.2)$ & 0.0118 \\
\hline \multicolumn{4}{|c|}{ Gleason score (biopsy), no. (\%) } \\
\hline$<7$ & $25(34.7)$ & $31(31.6)$ & 0.6720 \\
\hline 7 & $27(37.5)$ & $25(25.5)$ & 0.0952 \\
\hline$>7$ & $20(27.8)$ & $42(42.9)$ & 0.0449 \\
\hline \multicolumn{4}{|l|}{ Clinical T stage, no. (\%) } \\
\hline $\mathrm{T} 1 \mathrm{c}$ & $33(45.8)$ & $47(48.0)$ & 0.7838 \\
\hline $\mathrm{T} 2 \mathrm{a}$ & $21(29.2)$ & $22(22.4)$ & 0.3205 \\
\hline $\mathrm{T} 2 \mathrm{~b}$ & $11(15.3)$ & $19(19.4)$ & 0.4882 \\
\hline $\mathrm{T} 2 \mathrm{c}$ & $6(8.3)$ & $10(10.2)$ & 0.6803 \\
\hline $\mathrm{T} 3 \mathrm{a}$ & $1 \quad(1.4)$ & 0 & 0.9776 \\
\hline
\end{tabular}

the puboprostatic ligament is dissected from the prostate, and cut as close as possible to the prostate so that it can be sutured with the bladder neck later (Fig. 5a and b). This process releases the prostate from the pelvic floor and extends the membranous urethra, facilitating the retention of a longer membranous urethra. It also exposes the urethral sphincter attached to the pelvic floor (effective for prevention of sphincter muscle injury). Then, anastomosis of the bladder neck with the puboprostatic ligament (sling suspension of the bladder neck) is carried out.

Following the completion of bladder neck suturing at the 12 o'clock position, the preserved bilateral puboprostatic ligaments are stitched with the same thread, and sutured so as to place the bladder neck at the original position relative to the prostate, where the prostate was pulled by the puboprostatic ligaments before surgery (Fig. 5c). This process retains the physiological positions of the bladder and urethra close to those existing pre-operatively. The post-operative positions of the bladder in the pelvic floor and the relation- ship between the bladder and posterior urethra are evaluated from the ultrasonography image by measuring the 'bladderurethral angle', which is the angle between the posterior wall of the bladder and the membranous urethra when the bladder is filled with $50 \mathrm{ml}$ of water (Fig. 5d). A bladder-urethral angle of $>83$ degrees was considered to indicate successful execution of the sling suspension, as the average value of the bladder-urethral angle was $74.5 \pm 3.98$ (mean \pm SD) degrees in patients in this series before prostatectomy, and average value $+2 \mathrm{SD}$, was 82.6 degrees.

Key element 7: Reconstruction of the posterior support. The prostatic fascia and urethral rhabdosphincter are stitched with 2-0 Vicryl suture (Fig. 5g and h), and anchored with the remaining portion of the Denonvilliers' fascia cut on the urethral side (Fig. 5i and j). The musculofascial plate, reconstructed by joining the prostatic fascia, urethral rhabdosphincter, and the residuum of the Denonvilliers' fascia, is then sutured posteriorly to the bladder neck, passing 1-2 cm 
Table II. Pathological findings.

\begin{tabular}{|c|c|c|c|}
\hline Pathological findings & Group 1 & Group 2 & P-value \\
\hline \multicolumn{4}{|l|}{ Gleason score (pathology), no. (\%) } \\
\hline$<7$ & $9(12.5)$ & $12(12.2)$ & 0.9800 \\
\hline 7 & $12(16.7)$ & $23(23.5)$ & 0.2073 \\
\hline$>7$ & $38(52.8)$ & $54(55.1)$ & 0.0449 \\
\hline Post-hormonal, cancer (-) & $13(18.1)$ & $8(8.2)$ & 0.0215 \\
\hline \multicolumn{4}{|l|}{ Pathological T stage, no. (\%) } \\
\hline pT1 & $0 \quad(0)$ & $1 \quad(1.0)$ & 0.9761 \\
\hline $\mathrm{pT} 2 \mathrm{a}$ & $23(31.9)$ & $19(19.5)$ & 0.0628 \\
\hline $\mathrm{pT} 2 \mathrm{~b}$ & $18(25.0)$ & $40(40.8)$ & 0.0330 \\
\hline $\mathrm{pT} 2 \mathrm{c}$ & $10(13.9)$ & $6(6.1)$ & 0.0947 \\
\hline pT3a & $8(11.1)$ & $17(17.3)$ & 0.2602 \\
\hline pT3b & $2(2.8)$ & 8 (8.2) & 0.1593 \\
\hline Post-hormonal, cancer (-) & $11(15.3)$ & $6(6.1)$ & 0.0567 \\
\hline Pathological $\mathrm{N}$ stage $\left(\mathrm{pN}^{+}\right)$, no. $(\%)$ & 1 (1.4) & $0 \quad(0)$ & 0.9776 \\
\hline Surgical margin, no. $(\%)$ & $16(22.2)$ & $18(18.4)$ & 0.5053 \\
\hline Capsural invasion, no. (\%) & $12(16.7)$ & $25(25.5)$ & 0.2728 \\
\hline Seminal vesicle invasion, no. (\%) & $2(2.8)$ & $10(10.2)$ & 0.1030 \\
\hline Venous invasion, no. (\%) & $4 \quad(5.6)$ & $9(9.2)$ & 0.4709 \\
\hline Lymph duct invasion, no. (\%) & $6(8.3)$ & $10(10.2)$ & 0.8138 \\
\hline Nerve invasion, no. (\%) & $23(31.9)$ & $36(36.7)$ & 0.8051 \\
\hline
\end{tabular}

cranially, and then tightened. This process restores the posterior support tissue of the bladder and urethra. Combined with the bladder neck suspension by the puboprostatic ligaments, the bladder and urethra are retained at physiological positions close to those existing before surgery.

\section{Results}

Patient background. One hundred and seventy patients who underwent laparoscopic total prostatectomy at the Urology Department of Osaka Medical College between June 2007 and June 2010, were divided into 72 patients who were treated on the basis of all of the 7 key elements (group 1), and the other 98 patients (group 2) who were not. We analyzed the significance of each skill element for early recovery of continence and noted a significant difference between the two groups at all of the examined time-points, 1, 3, 6 and 12 months after surgery. Table I shows the backgrounds of the patients in the two groups.

Post-operative histopathological findings (Table II). The post-operative histopathological Gleason score was $\leq 6$ in 9 cases $(12.5 \%), 7$ in $12(16.7 \%)$, and $\geq 8$ or higher in 38 cases $(52.8 \%)$, with post-hormonal change (without cancer cells) being observed in 13 patients $(18.1 \%$ ) in group 1. In group 2, the score was $\leq 6$ in 12 cases $(12.2 \%), 7$ in $23(23.5 \%)$, and $\geq 8$ in 54 cases $(55.1 \%$ ), with post-hormonal change (without cancer cells) being observed in 8 patients (8.2\%) (Table II). There were no significant inter-group differences in the rate of surgical margin positivity ( 22.2 vs. $18.4 \%, \mathrm{p}=0.5053)$ or other histopathological findings, including the incidences of extracapsular, seminal vesicle, venous vascular, lymph vascular, or nerve invasion.

Urinary continence (Table III). We evaluated post-operative urinary continence in terms of the number of urinary pads used per day: Two parameters were compared between the groups at 1, 3, 6 and 12 months after surgery: i) Number of urinary pads, and ii) continence rate (the number of patients requiring 0 or only 1 urinary pad/the total number of patients). The number of urinary pads used after surgery was significantly reduced in the group treated according to the 7 key elements at all time-points after surgery, the median number being $4,1,0$, and 0 at 1, 3, 6 and 12 months, respectively, compared to 8, 5, 3 and 1 for the other group, thus indicating significantly improved post-operative urinary continence in group 1 ( $\mathrm{p}<0.0001 \mathrm{vs.} \mathrm{group} 2$ at all time-points). Moreover, application of the 7 key elements significantly improved the continence rate: More than half of such patients $[54.4 \% ; 95 \%$ confidence interval (CI), 41.9-66.5\%] achieved urinary continence within 3 months after surgery, >90\% (93.3\%; 95\% CI, 83.8-98.2\%) achieved it within 6 months, and all patients $(100 \%$; 95\% CI, 90.3-100\%) had achieved it within 12 months. In contrast, $<10 \%$ of group 2 patients $(8.5 \% ; 95 \%$ 
Table III. Continence status.

\begin{tabular}{|c|c|c|c|}
\hline Categories & Group 1 & Group 2 & P-value \\
\hline \multicolumn{4}{|c|}{ Number of pads used after surgery } \\
\hline \multicolumn{4}{|c|}{ At 1 month } \\
\hline Median & 4 & 8 & \multirow[t]{2}{*}{$<0.0001$} \\
\hline (Range; 1st-3rd QU) & $(0-10 ; 2-8)$ & $(0-15 ; 4-10)$ & \\
\hline \multicolumn{4}{|l|}{ At 3 months } \\
\hline Median & 1 & 5 & \multirow[t]{2}{*}{$<0.0001$} \\
\hline (Range; 1st-3rd QU) & $(0-8 ; 1-2)$ & $(0-15 ; 3-7)$ & \\
\hline \multicolumn{4}{|l|}{ At 6 months } \\
\hline Median & 0 & 3 & \multirow[t]{2}{*}{$<0.0001$} \\
\hline (Range; 1st-3rd QU) & $(0-3 ; 0-1)$ & $(0-10 ; 2-4)$ & \\
\hline \multicolumn{4}{|l|}{ At 12 months } \\
\hline Median & 0 & 1 & \multirow[t]{2}{*}{$<0.0001$} \\
\hline (Range; 1st-3rd QU) & $(0-1 ; 0-0)$ & $(0-10 ; 0-2)$ & \\
\hline \multicolumn{4}{|l|}{ Continence rate } \\
\hline \multicolumn{4}{|l|}{ At 1 month } \\
\hline No./total & $13 / 72$ & $4 / 98$ & \multirow[t]{2}{*}{0.0011} \\
\hline$(\% ; 95 \% \mathrm{CI})$ & $(22.2 ; 13.2-33.6)$ & $(4.1 ; 1.1-10.1)$ & \\
\hline \multicolumn{4}{|l|}{ At 3 months } \\
\hline No./total & $37 / 68$ & $8 / 94$ & \multirow[t]{2}{*}{$<0.0001$} \\
\hline$(\% ; 95 \% \mathrm{CI})$ & $(54.4 ; 41.9-66.5)$ & $(8.5 ; 3.7-16.1)$ & \\
\hline \multicolumn{4}{|l|}{ At 6 months } \\
\hline No./total & $56 / 60$ & $21 / 91$ & \multirow[t]{2}{*}{$<0.0001$} \\
\hline$(\% ; 95 \% \mathrm{CI})$ & $(93.3 ; 83.8-98.2)$ & $(23.1 ; 14.9-33.1)$ & \\
\hline \multicolumn{4}{|l|}{ At 12 months } \\
\hline No./total & $36 / 36$ & $33 / 58$ & \multirow[t]{2}{*}{0.0018} \\
\hline$(\% ; 95 \% \mathrm{CI})$ & $(100 ; 90.3-100)$ & $(56.9 ; 43.2-69.8)$ & \\
\hline
\end{tabular}

Table IV. Operative variables.

\begin{tabular}{|c|c|c|c|}
\hline Intra-operative findings & Group 1 & Group 2 & P-value \\
\hline \multicolumn{4}{|l|}{ Operation time (min) } \\
\hline Median (range) & $238(130-465)$ & $248(155-440)$ & 0.1653 \\
\hline 1st-3rd QU & $195-275$ & $210-285$ & \\
\hline \multicolumn{4}{|l|}{ Blood loss } \\
\hline Median (range) & $500(50-2450)$ & $473(50-2750)$ & 0.5756 \\
\hline 1st-3rd QU & $269-850$ & $302-700$ & \\
\hline \multicolumn{4}{|l|}{ Complications } \\
\hline Rectal injury (\%) & 0 & $1 / 98(1)$ & 0.9787 \\
\hline $95 \% \mathrm{CI}$ & 0 & $0.3-5.6$ & \\
\hline
\end{tabular}

CI, 3.7-16.1\%; $<<0.0001$ vs. group 1) achieved urinary continence within 3 months, <30\% (23.1\%; 95\% CI, 14.9-33.1\%; $\mathrm{p}<0.0001$ vs. group 2) achieved it within 6 months, and $<60 \%$ (56.9\%; 95\% CI, 43.2-69.8\%; $\mathrm{p}=0.0018$ vs. group 2) achieved it within 12 months. These results suggest that application of the 7 key elements is useful for early recovery of urinary continence.
Intra-operative findings (Table IV). The median operation time was 238 min [range; 1st-3rd quartile (QU), 130-465; 195-275] in group 1 and 248 min (range; 1st-3rd QU, 155-440; 210-285) in group 2, showing that the use of the 7 key elements did not significantly prolong the operation time (group 1 vs. group 2, $\mathrm{p}=0.1653$ ). The median blood loss volume was $500 \mathrm{ml}$ (range; 1st-3rd QU, 50-2450; 269-850) 
Table V. Post-operative course.

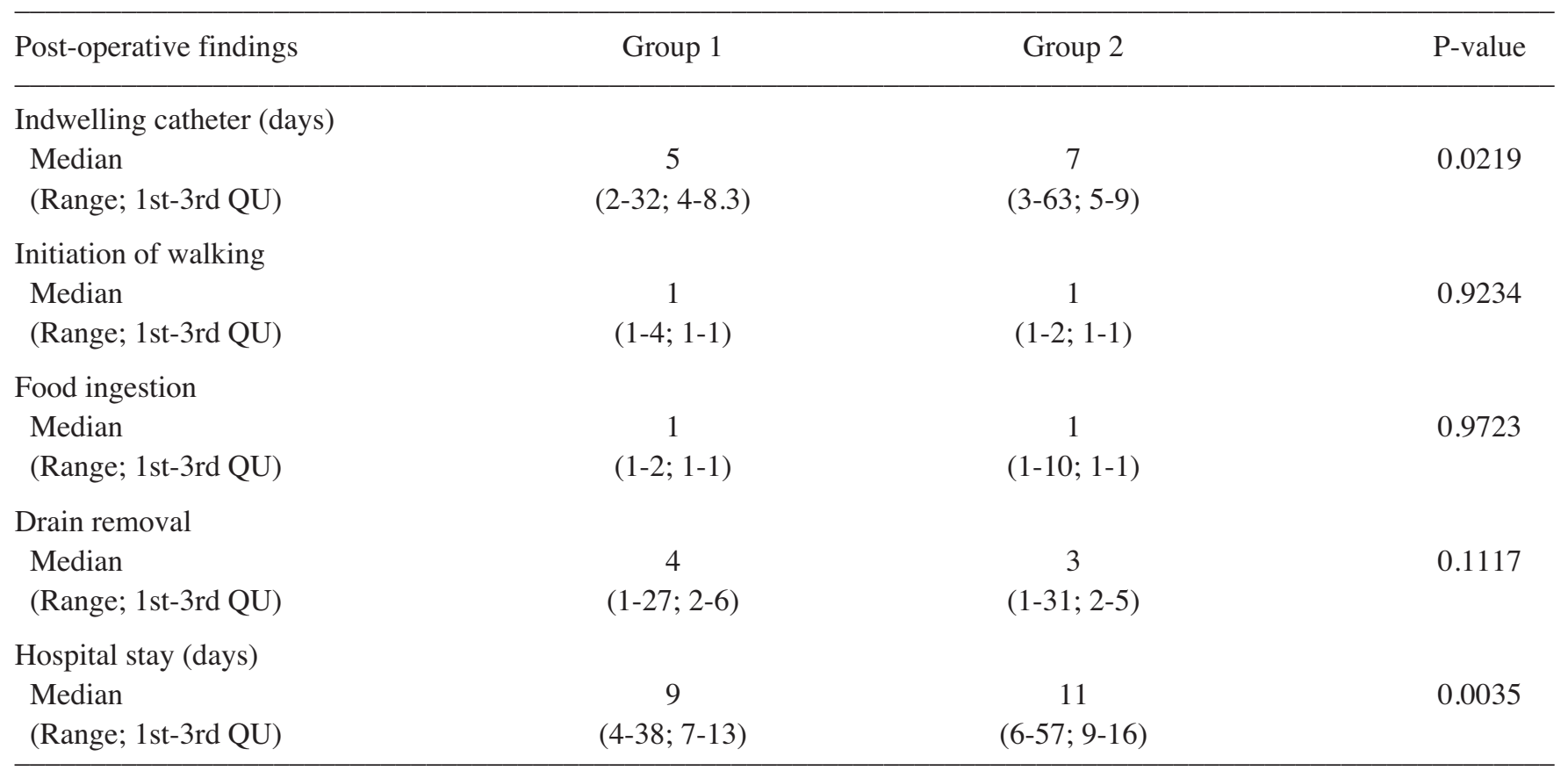

in group 1 and $473 \mathrm{ml}$ (range; 1st-3rd QU, 50-2750; 302-700) in group 2, showing that the use of the 7 key elements did not lead to a significant increase in blood loss (group 1 vs. group $2, \mathrm{p}=0.5756)$. With regards to intra-operative complications, rectal injury occurred in 1 patient in group 2, but laparoscopic repair was possible, and the post-operative course was smooth. No complications occurred in group 1 .

Post-operative course. The median duration of urethral catheter placement after surgery was 5 days (range, 2-32 days; 1st-3rd QU, 4-8.3 days) in group 1, and 7 days (range, 3-63 days; 1st-3rd QU, 5-9 days) in group 2, showing that the period of catheter placement was significantly shortened in the group treated with the 7 key elements (group 1 vs. group $2, p=0.0219$ ) (Table V). Additionally, the duration of hospital stay was significantly shortened in the group in which the 7 key elements were appllied: 9 days in group 1 and 11 days in group 2, $\mathrm{p}=0.0035$. Thus the application of the 7 key points could be useful for elderly patients.

\section{Discussion}

Among various complications after total prostatectomy, urinary incontinence is the major factor impairing postoperative quality of life. Among several items proposed by urological experts, we chose 7 elements of operative skill that allow earlier recovery of urinary function, based on our own experience of open surgery, as well as details from other studies (3-10). In principle, we tried to apply all of the 7 elements to allow early recovery of urinary continence in all patients, although in practice certain patients could not be treated with some of the elements. We retrospectively studied the relationship between the use of the 7 elements and the post-operative continence status in each patient, and examined the significance of each element for early recovery of urinary continence. Post-operative continence status was evaluated on the basis of two parameters: i) The number of urinary pads used per day, and ii) the continence rate (the number of patients requiring 0 or only 1 urinary pad/the total number of patients) at 1, 3, 6 and 12 months after surgery.

We found that patients who had been treated by employing all the 7 elements of operative skill required a significantly shorter period for continence recovery, with a reduced number of urinary pads and a greater continence rate at all the timepoints examined, 1, 3, 6 and 12 months after surgery, compared to all the other patients, including those who had received any combination of only 6 of the elements. These results suggest that the application of all the 7 key elements of operative skill is significantly useful for achieving early recovery of urinary continence, and that these elements could have a cooperative influence that encompasses all the essential components for urinary continence.

Although the exact mechanisms by which these 7 elements improve continence recovery are still unclear, the following scheme has been proposed. Total prostatectomy-induced post-operative urinary incontinence is considered to be caused by comprehensive dysfunction of the urethral sphincter associated with the following three components: (I) Collapse of the support tissue maintaining the normal anatomical positions of the intrapelvic organs, including the bladder and urethra, (II) injury to the urethral sphincter, and (III) collapse of innervation (3-6). The collapse of the support tissue of the intrapelvic organs includes the collapse of the endopelvic fascia forming the foundation structure of the intrapelvic organs, including the bladder and urethra, and the additional collapse of the Denonvillers' fascia continuing from the posterior surface of the bladder to the urethral sphincter, i.e., the 'posterior support' of the urethra and bladder $(5,6,11)$, and suspension of the vesico-urethral junction by the puboprostatic ligament, i.e., 'anterior support' $(3,4,10,12)$. The 
collapse of these supports alters the anatomical positions of the bladder and urethra, which can impair the function of the urethral sphincter.

Injury to the urethral sphincter includes injury to the external urethral sphincter, and disorder of sphincter function around the membranous urethra. Injury to the external urethral sphincter is caused mainly by electrocoagulation and bleeding from DVC can result in the excessive use of electrocoagulation. Functional disorder of the sphincter around the membranous urethra is usually due to cutting or injury in the region of attachment to the membranous urethra during surgery. This has been suggested by the significantly lower incidence of post-operative urinary incontinence when the sphincter muscle of the membranous urethra is long, as demonstrated by pre-operative MRI (13).

With regards to the collapse of innervation, Stolzenburg et al $(14,15)$ and Curto et al $(16)$ have reported significantly more favorable urinary continence in cases treated with nerve-sparing to preserve erectile function than in cases without such nerve-sparing, suggesting that pelvic nerve preservation leads to improvement of urinary continence.

The rationale for choosing the 7 elements of operative skill was based on the establishment of comprehensive countermeasures against the causes of post-operative urinary incontinence, I-III: (I) The collapse of the support tissue of the intrapelvic organs is tackled in three ways: i) The endopelvic fascia is preserved as much as possible to retain the structure of the pelvic floor, ii) the urethral rhabdosphincter, the stump of the Denonvillers' fascia, and the posterior surface of the bladder are sutured, as proposed by Rocco et al $(5,6)$, to repair the posterior support of the bladder and urethra, and iii) the puboprostatic ligaments are preserved as much as possible to suspend the site of vesico-urethral anastomosis (the sling suspension technique) and repair the anterior support. As an index of the anatomical positions of the intrapelvic organs, including the bladder and urethra, we measured the bladder-urethral angle using transrectal ultrasonography. A bladder-urethral angle exceeding 83 degrees, which was the value of the average bladder-urethral angle $+2 \mathrm{SD}$ in patients in this series before prostatectomy, was considered to represent successful execution of the 'sling-suspension'.

(II) To prevent the second cause of incontinence, injury to the urethral sphincter, care should be taken to avoid any manipulation of the external urethral sphincter, whether it be technical injury or electrocoagulation. Ligation of the DVC should be performed entirely by the bunching procedure, which prevents excessive bleeding and protects the external urethral sphincter from injury due to electrocoagulation. To avoid any functional disorder of the sphincter of the membranous urethra, as much of the membranous urethra as possible should be preserved in order to retain the attachment of the urethral sphincter around it, i.e., sphincter preservation. Transrectal ultrasonography imaging could be of great assistance in the preservation of the membranous urethra, and this was confirmed by measuring its remaining length on the ultrasonography image. When $>2.1 \mathrm{~cm}$ of the membranous urethra was preserved, we considered that urethral preservation was successful, as the average length of the membranous urethra in addition to double the value of standard deviation
$($ mean $+2 \mathrm{SD})$ in the patients in this series before prostatectomy, was $2.11 \mathrm{~cm}(1.65+0.23 \times 2)$.

(III) The collapse of innervation is prevented by preservation of the pelvic nerves as much as possible through bilateral nerve-sparing. The color Doppler ultrasound image, which visualizes the neurovascular bundle, is of great assistance in achieving more reliable and accurate nervesparing surgery and, as a visual index, contributes to the more precise evaluation of surgical success.

Although further investigation will be necessary to clarify how and to what extent each element of operative skill contributes to the early recovery of urinary continence, the application of the 7 key elements led to an apparent improvement of post-operative urinary continence in this series of patients, suggesting that these elements improve the overall function of the sphincter.

Another important issue with regards to the establishment of the 7 key elements as a standard clinical approach is that there was no significant negative influence on other surgical parameters, such as prolongation of the operation time and an increase in the rate of histopathological stump positivity due to bilateral nerve-sparing. Curt et al (16) and Stolzenburg et al $(14,15)$ reported that bilateral nerve-sparing did not increase the positive surgical margin rate. Additionally, our novel approach employing TRUS guidance, which provides a sagittal image of the pelvic organs including the prostate, bladder and rectum in real-time and from any angle, could also play an important role in reducing the incidence of intraoperative complications, with no elevation of the rate of surgical margin positivity.

In conclusion, although further investigation will be necessary, the present findings suggest that the application of the 7 key elements using TRUS guidance could be valuable for the minimization of urinary incontinence after prostate surgery.

\section{References}

1. Kawakita M, Sato M, Oguchi N, Muguruma K, Murota T and Matsuda T: [Transperitoneal laparoscopic radical prostatectomy with the Montsouris technique: experience in initial 5 cases]. Nippon Hinyokika Gakkai Zasshi 92: 506-512, 2001.

2. Hoshi A, Hanai T, Hanai K, et al: [Clinical evaluation of postoperative urinary incontinence after laparoscopic radical prostatectomy: 'cross sectional study based on the original questionnaire']. Hinyokika Kiyo 53: 31-37, 2007.

3. Tewari A, Jhaveri J, Rao S, et al: Total reconstruction of the vesico-urethral junction. BJU Int 101: 871-877, 2008.

4. Tewari AK, Bigelow K, Rao S, et al: Anatomic restoration technique of continence mechanism and preservation of puboprostatic collar: a novel modification to achieve early urinary continence in men undergoing robotic prostatectomy. Urology 69: 726-731, 2007.

5. Rocco B, Gregori A, Stener S, et al: Posterior reconstruction of the rhabdosphincter allows a rapid recovery of continence after transperitoneal videolaparoscopic radical prostatectomy. Eur Urol 51: 996-1003, 2007.

6. Rocco F, Carmignani L, Acquati P, et al: Restoration of posterior aspect of rhabdosphincter shortens continence time after radical retropubic prostatectomy. J Urol 175: 2201-2206, 2007.

7. Walz J, Burnett AL, Costello AJ, et al: A critical analysis of the current knowledge of surgical anatomy related to optimization of cancer control and preservation of continence and erection in candidates for radical prostatectomy. Eur Urol 57: 179-192, 2010 .

8. Ukimura O, Gill IS, Desai MM, et al: Real-time transrectal ultrasonography during laparoscopic radical prostatectomy. J Urol 172: 112-118, 2004. 
9. Takenaka A, Soga H, Sakai I, et al: Influence of nerve-sparing procedure on early recovery of urinary continence after laparoscopic radical prostatectomy. J Endourol 23: 1115-1119, 2009.

10. Rehder P and Gozzi C: Transobturator sling suspension for male urinary incontinence including post-radical prostatectomy. Eur Urol 52: 860-867, 2007

11. Rocco F, Carmignani L, Acquati P, et al: Early continence recovery after open radical prostatectomy with restoration of the posterior aspect of the rhabdosphincter. Eur Urol 52: 376-383, 2007.

12. Noguchi M, Kakuma T, Suekane S, Nakashima O, Mohamed ER and Matsuoka K: A randomized clinical trial of suspension technique for improving early recovery of urinary continence after radical retropubic prostatectomy. BJU Int 102: 958-963, 2008.
13. Nguyen L, Jhaveri J and Tewari A: Surgical technique to overcome anatomical shortcoming: balancing post-prostatectomy continence outcomes of urethral sphincter lengths on preoperative magnetic resonance imaging. J Urol 179: 1907-1911, 2007.

14. Stolzenburg JU, Rabenalt R, Do M, et al: Intrafascial nervesparing endoscopic extraperitoneal radical prostatectomy. Eur Urol 53: 931-940, 2008.

15. Stolzenburg JU, Liatsikos E, Rabenalt R, et al: Nerve sparing endoscopic extraperitoneal radical prostatectomy - effect of puboprostatic ligament preservation on early continence and positive margins. Eur Urol 49: 103-112, 2006

16. Curto F, Benijts J, Pansadoro A, et al: Nerve sparing laparoscopic radical prostatectomy: our technique. Eur Urol 49: 344-352, 2006. 